\title{
In-situ experimental equipment to predict corrosion fatigue behavior of materials exposed to corrosive environment
}

\author{
${ }^{1}$ Anja Pfennig, ${ }^{2}$ Marcus Wolf \\ ${ }^{1}$ HTW University of Applied Sciences Berlin, Wilhelminenhofstraße 75 A, Gebäude C, 12459 Berlin \\ ${ }^{2}$ BAM Federal Institute of Materials Research and Testing, Unter den Eichen 87, 12205 Berlin
}

Correspondence Author: Anja Pfennig, Department of Engineering, HTW University of Applied Sciences Berlin, Wilhelminenhofstraße 75 A, Gebäude C, 12459 Berlin,

E-mail: anja.pfennig@htw-berlin.de Ph: 00493050194231

Received date: 22 December 2018, Accepted date: 22 January 2018, Online date: 28 February 2018

Copyright: (C) 2018 Anja Pfennig. This is an open-access article distributed under the terms of the Creative Commons Attribution License, which permits unrestricted use, distribution, and reproduction in any medium, provided the original author and source are credited.

\begin{abstract}
In CCS environment (carbon capture and storage) pipes and in geothermal power plants the materials used in pumps are loaded static and/or cyclically and at the same time exposed constantly to the highly corrosive hot thermal water. Experimental procedures such as ambient pressure immersions tests, in-situ corrosion fatigue experiments with a test set up and corrosion chamber for ambient pressure and in-situ corrosion fatigue experiments under push-pull load and rotation bending load as well as in-situ corrosion fatigue experiments at high pressure are introduced. Given as an example of the corrosion fatigue behavior of high alloyed steels in geothermal environment the lifetime reduction of AISI 420 (X46Cr13, 1.4043) and AISI630 (X5CrNiCuNb16-4, 1.4542) is demonstrated (T=60 ${ }^{\circ} \mathrm{C}$, geothermal brine: Stuttgart Aquifer flow rate: 9 l/h, CO2). S-N plots, micrographic-, phase-, fractographic- and surface analysis were applied to obtain sustainable information
\end{abstract}

Keywords: Corrosion Fatigue, High Cycle Fatigue, Steel, Ccs, Co2-Storage, Geothermal Energy, In-Situ Experiments

\section{INTRODUCTION}

Materials in geothermal power plants are loaded cyclically under pressure and exposed constantly to the highly corrosive hot thermal water (up to ca. $200{ }^{\circ} \mathrm{C}$, ca. 100 bar, ca. $20 \%$ salinity of the geothermal water) where fluid properties may differ strongly (Giese, L.B.2001). This leads to corrosion fatigue and thus inevitably to the reduction of the lifetime of these components. The influence of frequency, temperature and chloride concentration on the corrosion fatigue behaviour is very well known in literature (Thomas, J.P.and R.P. Wei, 1992). In general corrosion processes with or without applied mechanical stress are enhanced, especially in steels with low chromium content (Mu, L.J., W.Z. Zhao, 2010), with the presence of chloride (Unigovski, et al., 2009), hydrogen sulfide $\left(\mathrm{H}_{2} \mathrm{~S}\right)$ (Holtam, et al., 2010) and $\mathrm{CO}_{2}$ (Thorbjörnsson, I., 1995). The endurance limit (Roeder, et al., 1992) will decrease with increasing temperature, increasing mechanical load and decreasing $\mathrm{pH}$ for high alloyed steels. But increasing chromium content of steels as well as internal compressive stress in surface regions will increase the endurance limit (Ebara, R.,).

This work was carried out to assess the influence of corrosive media on the cyclically loaded mechanical behaviour of stainless steels in geothermal energy production. Therefore special reaction vessels for ambient and high pressure static corrosion experiments were set up. Furthermore new corrosion chambers for insitu corrosion fatigue experiments were designed (Pfennig, et al., 2013) to gain knowledge upon the corrosion behavior of steels in downhole equipment surrounded by geothermal environments.

Ambient and high pressure vessels for in-situ testing - immersion tests

Laboratory scale exposure tests in $\mathrm{CO}_{2}$-saturated aquifer brine and water saturated $\mathrm{CO}_{2}$ may be carried out using coupons of the steels qualities with 8 mm thickness, $20 \mathrm{~mm}$ width, $50 \mathrm{~mm}$ length. A hole of $3.9 \mathrm{~mm}$ diameter is used for sample positioning. Samples of each base metal are positioned within the vapour phase and within the liquid phase. Flow control (3 NL/h) of the technical $\mathrm{CO}_{2}$ (purity 99,995 vol.-\%)) into the brine (Förster, et al., 2006) at ambient pressure was done by a capillary meter GDX600_man by QCAL Messtechnik GmbH, Munich. The exposure of the samples between $700 \mathrm{~h}$ to $8000 \mathrm{~h}$ was disposed in reaction vessels according to the conditions at the geological site at $60^{\circ} \mathrm{C}$ at ambient pressure - each material in a separated reaction vessel (Pfennig, A., R. Bäßler, 2009), (Wolf, et al., 2016) and at 100 bar (Pfennig, et al., 2014), (Pfennig, et al., 2016) (Fig. 1).

Before corrosion tests the surfaces of the steels are activated by grinding with SiC-Paper down to $120 \mu \mathrm{m}$ under water. After the corrosion tests, the samples are cut partly for scale analysis with the corrosion layer and prepared partly for kinetic analysis after the scale was etched. Descaling of the samples was performed by exposure to $37 \% \mathrm{HCl}$. Then parts of the samples are embedded in a cold resin (Epoxicure, Buehler), cut and polished first with SiC-Paper from $180 \mu \mathrm{m}$ to 1200 $\mu \mathrm{m}$ under water and then finished with diamond paste $6 \mu \mathrm{m}$ and $1 \mu \mathrm{m}$. 

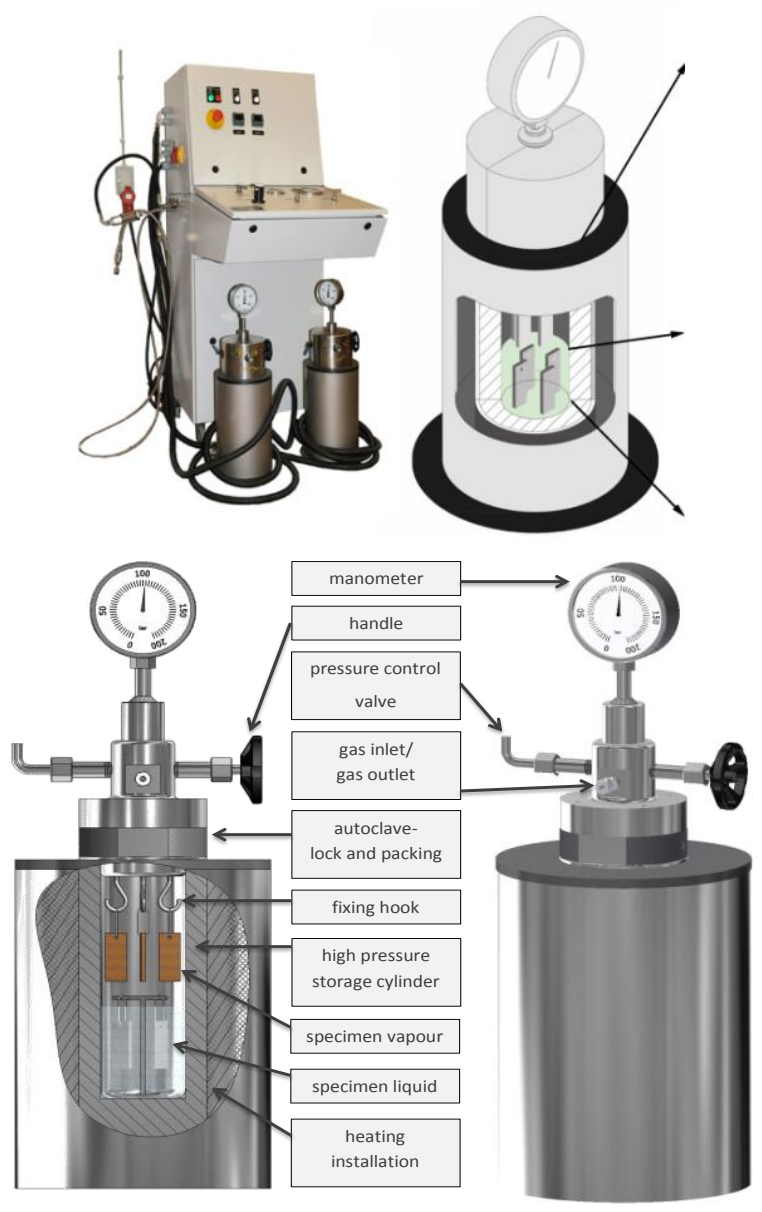

Fig. 1: Reaction vessels and experimental set up.

Corrosion chamber for in-situ testing of corrosion fatigue at ambient pressure:

The objective was to simulate in-situ conditions (temperature up to $100{ }^{\circ} \mathrm{C}$, corrosive environment) of a material exposed to dynamic mechanical stress and corrosive gas- saturated saline aquifer environment, such as components in geothermal power plant (Fig. 2).
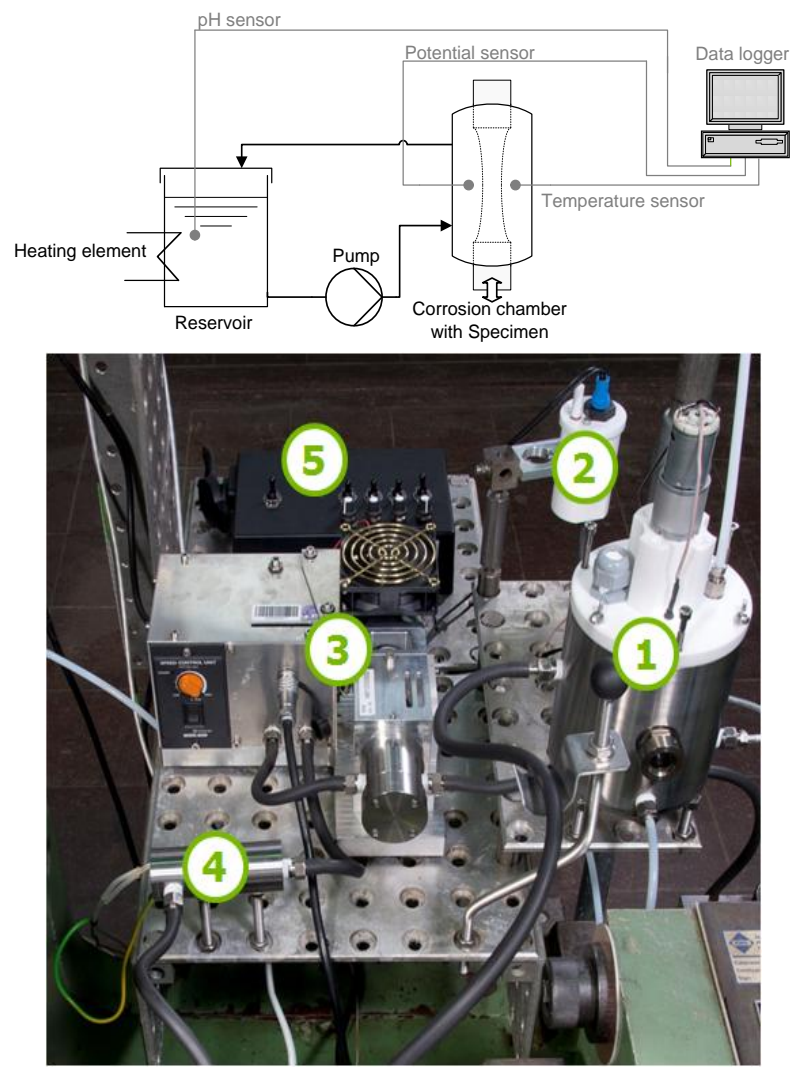


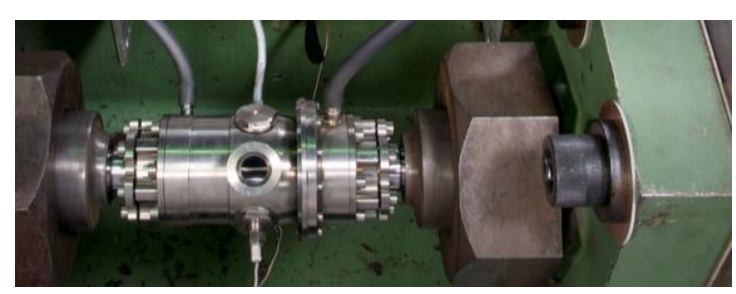

Fig. 2: Schematic set-up of operating corrosion chamber for in-situ corrosion fatigue testing (Wolf, et al., 2016)( Pfennig, et al., 2014).

This allows to assess materials of components loaded cyclically and exposed constantly to the highly corrosive hot thermal water with high salinity and differing fluid properties (Förster, et al., 2006). Highlight is the corrosion chamber fixed directly onto the sample leaving the resonant testing machine (Fig. 3) unaffected (Fig. 3- 5).

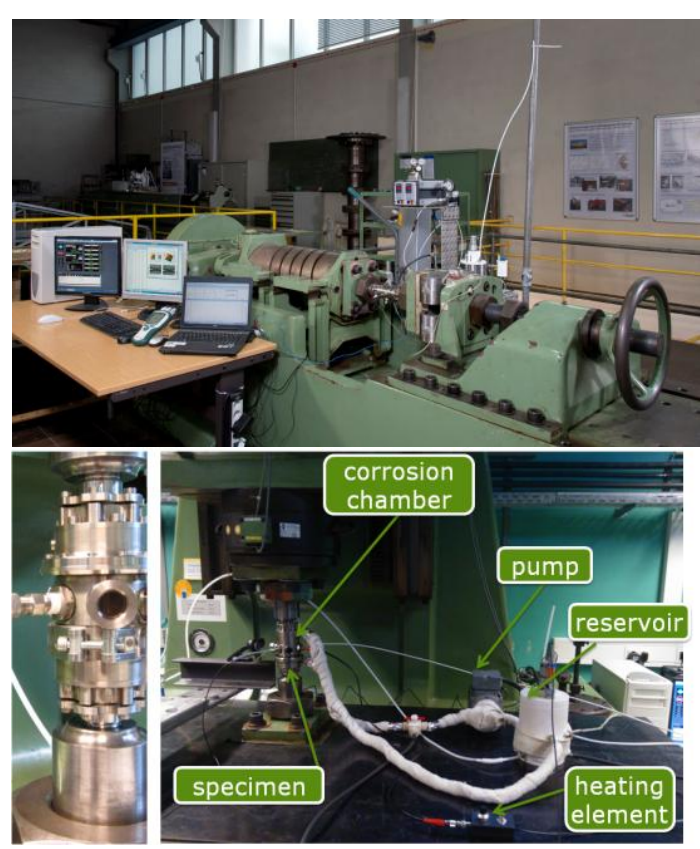

Fig. 3: Horizontal (top) and vertical (bottom) resonant testing machine for in-situ corrosion fatigue testing (Wolf, et al., 2016)( Pfennig, et al., 2014).

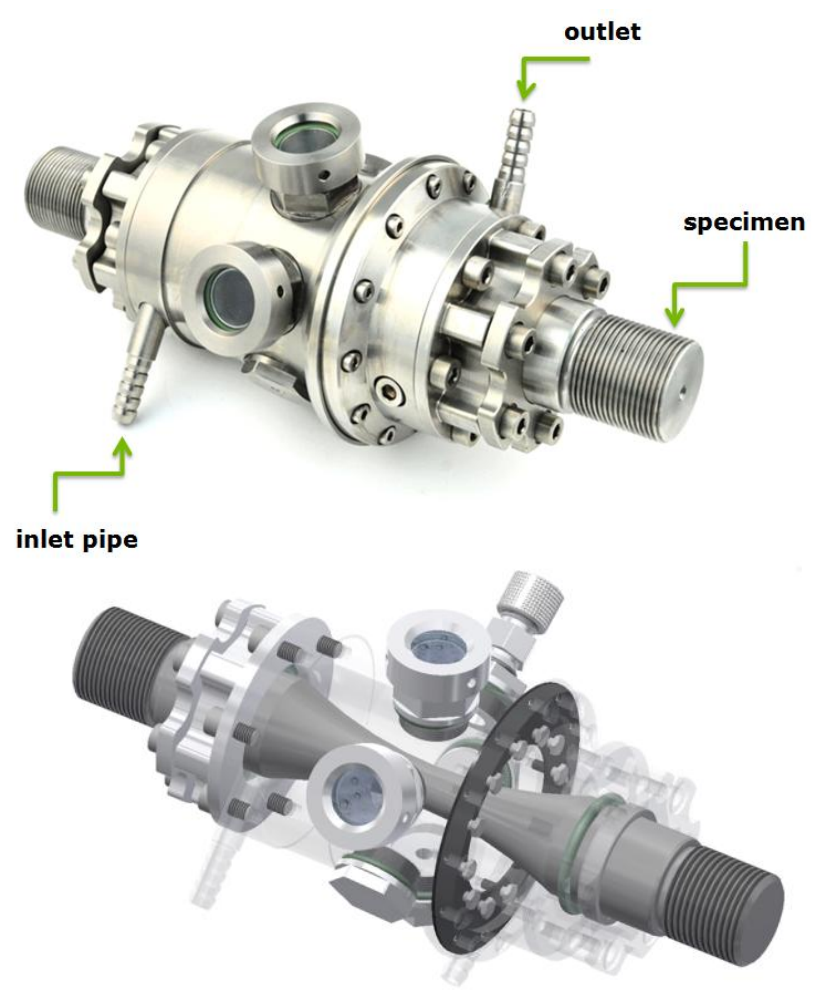

Fig. 4: Corrosion chamber for in-situ corrosion fatigue testing (Wolf, et al., 2016)( Pfennig, et al., 2014). 
During mechanical stress-strain tests a magnetically driven gear pump (3) constantly pumps the corrosive media from the reservoir (1) to the corrosion-and temperature-resistant corrosion chamber (bottom) surrounding the test specimen (Fig. 4 and Fig. 5)). Heating is realized by two independent heating elements (4). The test conditions are controlled via control unit (5). The ratio of sample surface to volume of the corrosive media after DIN 50905 Part 1 (10 ml/cm²) is greater than required. The connecting of the chamber onto the specimen via clamping collar creates a force-fit process ensuring enough force to the corrosion chamber at high frequencies to keep it firmly on the test specimen (Fig. 3). The corrosion chamber is sealed in the area of restraint over 0-rings made of Viton. In order not to impede the change in length occurring during the experiment, the corrosion chamber has a membrane as a motion-compensating element (Wolf, et al., 2016)( Pfennig, et al., 2014).

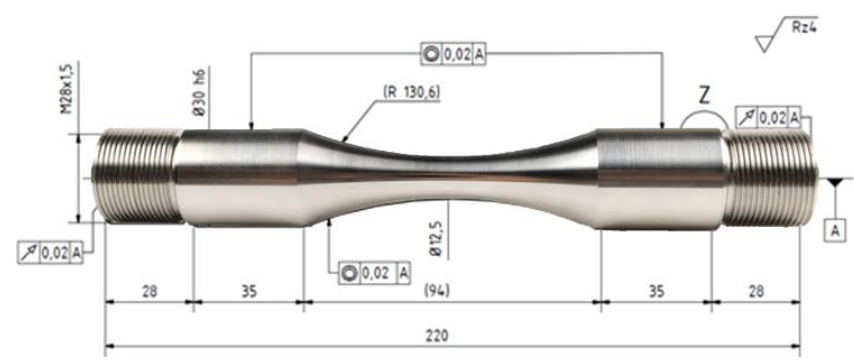

Fig. 5: Specimen for in-situ dynamic stress-strain testing in corrosive environment at high temperature (Wolf, et al., 2016)( Pfennig, et al., 2014).

Electrochemical data is collected during the mechanical tests as well as temperature, pH and electrochemical potential. For measurement of the electrochemical potential a shock resistant silver-silver chloride electrode was fixed in a Teflon channel (Fig. 6) (Pfennig, et al., 2014). To simulate non-static operation a resonant testing machine has been used at $30-40 \mathrm{~Hz}$ where samples of both steels were tested in stress-strain mode under CCS aquifer environment. In addition technical $\mathrm{CO}_{2}$ was introduced into the closed system at a rate close to $9 \mathrm{~L} / \mathrm{h}$ to keep stable environmental conditions.

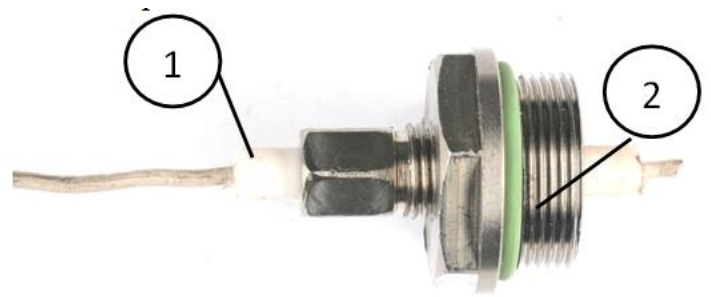

Fig. 6: Silver-silver chloride sensor adapted to the corrosion chamber (Pfennig, et al., 2013).

Dynamic in-situ corrosion experiments at ambient pressure (hcf):

The corrosion fatigue strength of stainless steel with $13 \%$ and $16 \%$ chromium (X46Cr13, 1.4043 and $\mathrm{X} 5 \mathrm{CrNiCuNb} 16-4,1.4542$, hardened and tempered with martensitic microstructure) is examined in dynamic stress-strain tests in $\mathrm{CO}_{2}$-saturated aquifer (Stuttgart Aquifer, Förster, et al., 2006) at $60{ }^{\circ} \mathrm{C}$. Therefore a resonant testing machine (sinusoidal dynamic test loads, $\mathrm{R}=-1$; resonant frequency $\sim 30 \mathrm{~Hz}$ ) has been used. In addition technical $\mathrm{CO}_{2}$ was introduced into the closed corrosion chamber system at a rate close to $9 \mathrm{~L} / \mathrm{h}$ to keep stable environmental conditions. In each test series 30 specimens were tested. The steels was tested between $150 \mathrm{MPa}$ and $500 \mathrm{MPa}$. Due to the rather heterogeneous fine machined surfaces (surface roughness $\mathrm{Rz}=4$ ) the specimens are comparable with prefabricated parts.

Without corrosive environment the fatigue strength of the material (theoretically an infinite number of load cycles without failure) has a relatively smooth slope (Fig. 7 and Fig. 8).

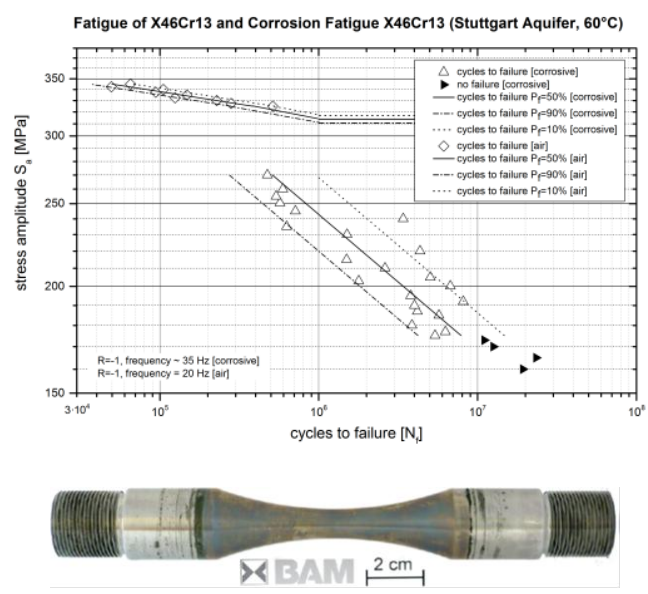

Fig. 7: S-N-curve of X46Cr13 (Pfennig, et al., 2013) and specimen after testing in air and in the corrosion chamber, exposed to flowing saline aquifer (Förster, et al., 2006) and $\mathrm{CO}_{2}$.

The decrease of the fatigue limit line of 1.4542 samples with increasing number of cycles (Wöhler-exponent of $\mathrm{k}=3,59$ ) is much larger in corrosive environment than in air (tensile strength in air: $1078 \mathrm{MPa}$, largest number of cycles in corrosive environment $\left(0,6 \mathrm{x} 10^{7}\right.$ at $\left.200 \mathrm{MPa}\right)$. Compared to 1.4034 (Fig. 7$)$ (Pfennig, et al., 2013) no typical fatigue strength of 1.4542 exists as shown in a log-log plot (Fig. 8). 


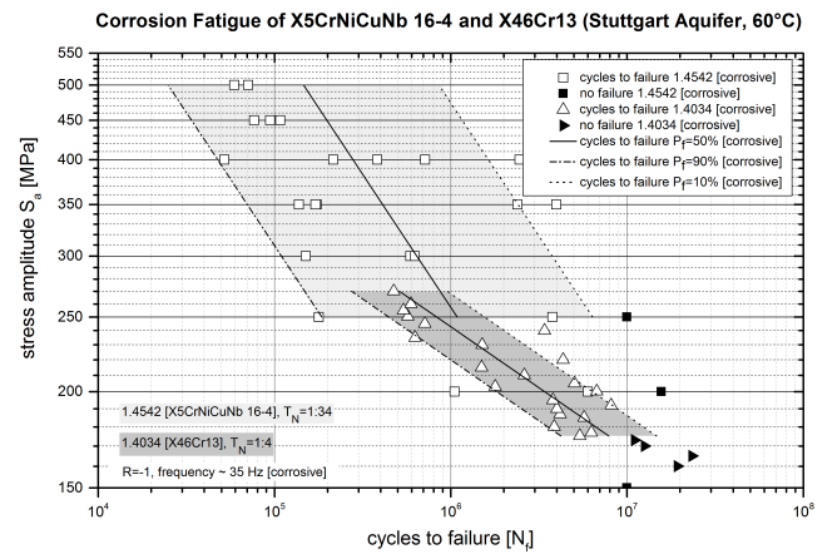

Fig. 8: S-N-curve and sample of 1.4542 (Pfennig, et al., 2013) exposed to flowing saline aquifer (Förster, et al., 2006) and $\mathrm{CO}_{2}$ at $60{ }^{\circ} \mathrm{C}$.

The coefficient of correlation $r^{2}=0.33$ from the regression is so small that doubt on the hypothesis of a (linear) relationship of the considered variables exist. In addition, the scattering range $\mathrm{TN}=1: 34,4$ is disproportionately large [9] compared to the scatter range of X46Cr13 of only 1:4. The corrosion fatigue strength of $\mathrm{X} 46 \mathrm{Cr} 13$ is approx. $36 \%$ below the endurance limit measured in air. $\mathrm{X} 5 \mathrm{CrNiCuNb} 16-4$ is $60 \%$ below the endurance limit measured in air.

Crack formation is correlated with pit corrosion phenomena resulting in inter-crystalline corrosion, but only for $\mathrm{X} 46 \mathrm{Cr} 13 \mathrm{failure}$ is a consequence of local corrosion (Fig. 9).

$\mathrm{X} 46 \mathrm{Cr} 13$
- $(1.4034$, AISI $420 \mathrm{C})$
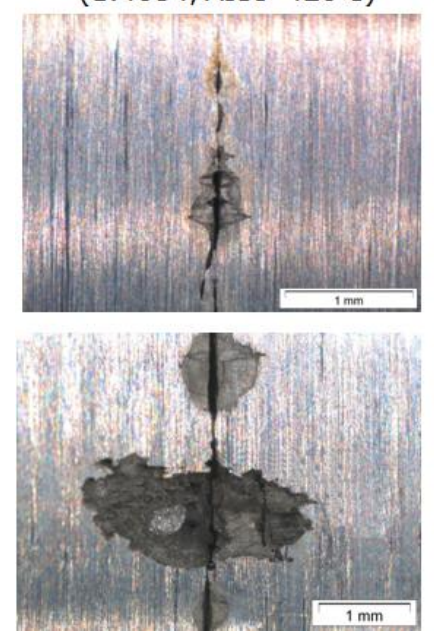

- X5CrNiCuNb16-4

- (1.4542, AISI 630)
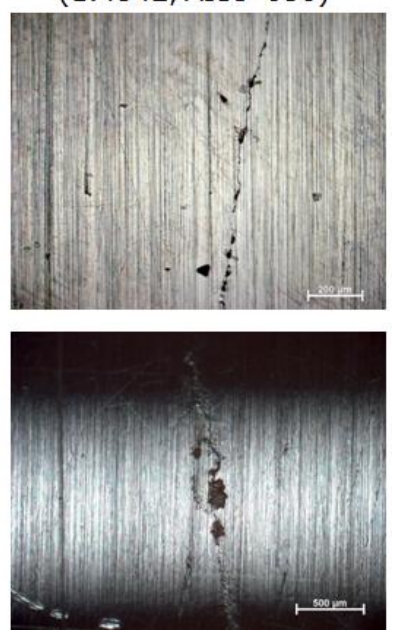

Fig. 9: Sample surfaces after testing (left: $\mathrm{X} 46 \mathrm{Cr} 13$, right: $\mathrm{X} 5 \mathrm{CrNiCuNb} 16-4$. Local corrosion leads to crack initiation and is most likely failure cause for $\mathrm{X} 46 \mathrm{Cr} 13$.

Corrosion chamber for in-situ testing testing of corrosion fatigue at high pressure:

The corrosion chamber for ambient pressure was constantly modified and adapted to high pressure experiments. For electrochemical measurement the testing machine was isolated in the area of restraint and one the other hand appropriate sensors were constructed for measurement (Fig. 6).

The fatigue test system was then modified according to the following boundary conditions (Wolf, M., 2013):

- temperature of the media: $200{ }^{\circ} \mathrm{C} /$ media pressure: 200 bar

- the specimen has to be surrounded by the gaseous und liquid media

- minimal volume of the chamber

- components have to meet technical regulation standards

- components chemically stabilized

- chamber may not constrict the strain of the specimen

- clamping device should not be exposed to the media

- corrosive vapour may be added facultatively

The directive DGRL in Germany regulates every pressure equipment at or above 0,5 bar in the European Union (Kommission, 2013)( Verband der Technischen Überwachungs-Vereine, 2000)( Richtlinie, 1997). It enjoins full responsibility in regard to design, production and testing of the pressure machine. Through the EC Declaration of Conformity the producer endorses the adherence of the declaration of the DGRL. The tolerable engineering standards for conversion of the directive for pressure machines (97/23/EG) are (Wagner, 2007):

- DIN EN 13445 unfired pressure vessels

- DIN EN 13480 metallic industrial piping

- DIN EN 12953 water-tube boilers

- DIN EN 12542 LPG Equipment and accessories

- DIN EN 12817 - 12820 LPG Equipment and accessories

- DIN EN 10216 seamless steel tubes for pressure purposes

- DIN EN 10217 welded steel tubes for pressure purposes

- DIN EN 1092 steel flanges

An alternative solution is the consultative document of the "Arbeitsgemeinschaft Druckbehälter" (AD) (Kommission, 2013). Indeed these consultative documents don't have the status of harmonized standards, but they do equate to the European pressure machine directive (97/23/EG) (Verband der Technischen 
Citation: Anja Pfennig, 2018. In-situ experimental equipment to predict corrosion fatigue behavior of materials exposed to corrosive environment. Journal of Applied Sciences Research., 14(1): 25-31.

Überwachungs-Vereine, 2000).

Figure 10 shows the cross section of the pressure corrosion chamber with affixed specimen. To avoid direct contact of the corrosive medium with the specimen, the chamber uses a quench (2) which is placed directly behind the hose-connecting point (1). The quench splits the jet and bypasses it around the specimen. At the same pitch the casing of the temperature sensor is set as counterpart (3). The casing serves the purpose to protect the temperature sensor of the corrosive medium.

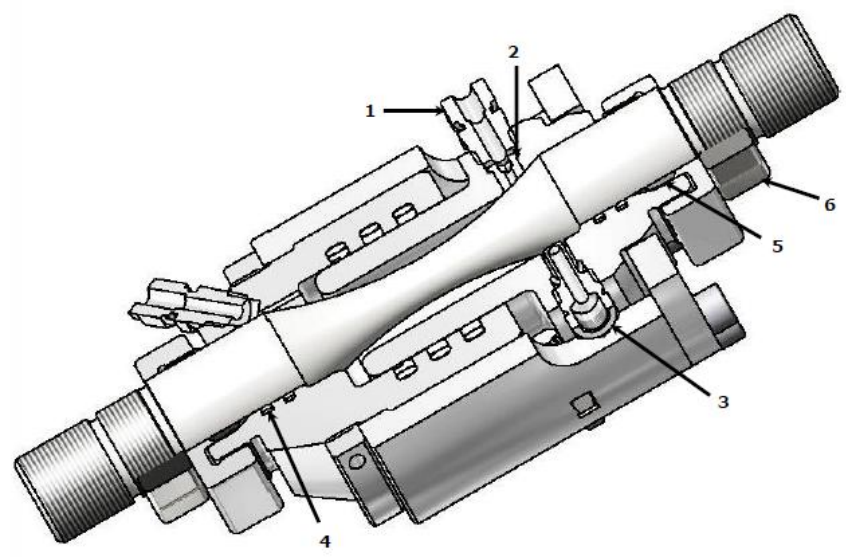

Fig. 10: 3D schematic drawing of the high pressure corrosion chamber. All right are reserved to M. Wolf (Wolf, M., 2013).

The pressure in the corrosion chamber is sealed by two serial connected rod seals (4) on the specimen. Due to the fact that the high corrosive load is affects the stability of these seals during testing and long term stability cannot be guaranteed a second sealing system is attached behind. The second sealing system is a metallic force-fitting (5) of the same type used for securing pipe-fittings. To retain the position of the specimen and prevent it is slipping, nuts (6) are installed on the lower and upper end of the specimen.

The pressure corrosion chamber is still in the procedure of being set up. The authors hope to begin experimental trials soon.

Conclusions:

Experimental test set-ups for immersion tests at high temperature (up to $200-400{ }^{\circ} \mathrm{C}$ ) and ambient pressure as well as high pressure (up to 200 bar) were introduced, to predict the corrosion behavior in highly corrosive geothermal aquifer water with addition of flowing corrosive gasses, such als $\mathrm{CO}_{2}$.

A highly flexible corrosion chamber allowing for electrochemical testing, $\mathrm{O}_{2}$-partial pressure or gas partial pressure measurement was designed to support stress-strain loaded corrosion fatigue experiments by enabling an in-situ corrosive environment which may be used up to $100{ }^{\circ} \mathrm{C}$ at ambient pressure.

The corrosion fatigue behaviour of $\mathrm{X} 46 \mathrm{Cr} 13,1.4043$ and $\mathrm{X} 5 \mathrm{CrNiCuNb} 16-4,1.4542$ may be described by statistical crack initiation but characteristic crack propagation and fracture surfaces for one stress amplitude. A typical fatigue strength of the S-N-curve does not exist under CCS corrosive conditions. The fatigue strength of the material in non-corrosive conditions of about $310 \mathrm{MPa}$ for X46Cr13 and $340 \mathrm{MPa}$ for X5CrNiCuNb16-4 is reduced significantly due to corrosion. Under these conditions the maximal number of cycles to failure observed was $1.10 \times 107$ at stress amplitude $173 \mathrm{MPa}$ for X46Cr13 and $10 \times 106$ at stress amplitude $150 \mathrm{MPa}$ for $\mathrm{X} 5 \mathrm{CrNiCuNb} 16-4$. Crack formation is correlated with pit corrosion phenomena resulting in inter crystalline corrosion, but only for $\mathrm{X} 46 \mathrm{Cr} 13$ failure is a consequence of local corrosion. (Pfennig, et al., 2013)

\section{ACKNOWLEDGEMENTS}

This work was supported by the FNK (Fachkonferenz für wissenschaftliche Nachwuchskräfte) of the Applied University of Berlin, HTW and by IMPACT (EU-Project EFRE 20072013 2/21).

\section{REFERENCES}

Ebara, R., Corrosion fatigue crack initiation behaviour of stainless steels, Procedia Engineering, 2: 1297-1306.

Förster, A., B. Norden, K. Zinck-Jørgensen, P. Frykman, J. Kulenkampff, E. Spangenberg, J. Erzinger, M. Zimmer, J. Kopp, G. Borm, C. Juhlin, C. Cosma,

S. Hurter, 2006. Baseline characterization of the CO2SINK geological storage site at Ketzin, Germany: Environmental Geosciences, $13(3)$ : $145-161$.

Giese, L.B.2001. Geochemie der Formationsfluide der Bohrung E Groß Schönebeck 3/90, STR02/14, Geothermie Report, 02-1: $145-169$.

Holtam, C.M., D.P. Baxter, I.A. Ashcroft, R.C. Thomsen, 2010. Effect of crack depth on fatigue crack growth rates for a C-Mn pipeline steel in a sour environment, International Journal of Fatigue, 32: 288-296.

Kommission, 2013. Europäische. Druck- und Gasgeräte. [Online] 9. Januar 2013http://ec.europa.eu/enterprise/sectors/pressure-andgas/documents/ped/guidelines/index_de.htm.

$\mathrm{Mu}$, L.J., W.Z. Zhao, 2010. Investigation on carbon dioxide corrosion behavior of HP13Cr110 stainless steel in simulated stratum water, Corrosion Science, 52: $82-89$.

Pfennig, A., H. Wolthusen, A. Kranzmann, 2016. Unusual corrosion behavior of 1.4542 exposed a laboratory saline aquifer water CCS-environment, GHGT13, November 14th-18th 2016, Lausanne, Switzerland.

Pfennig, A., K. Heynert, M. Wolf, T. Böllinghaus, 2014. First in-situ Electrochemical Measurement During Fatigue Testing of Injection Pipe Steels to Determine the Reliability of a Saline Aquifer Water CCS-site in the Northern German BasinOriginal, Energy Procedia, 63: 5773-5786.

Pfennig, A., R. Bäßler, 2009. Effect of CO2 on the stability of steels with 1\% and 13\% Cr in saline water, Corrosion Science, 51(4): 931-940.

Pfennig, A., R. Wiegand, M. Wolf, C.P. Bork, 2013. Corrosion and corrosion fatigue of AISI $420 \mathrm{C}(\mathrm{X} 46 \mathrm{Cr} 13)$ at $60{ }^{\circ} \mathrm{C}$ in $\mathrm{CO}_{2}$-saturated artificial geothermal brine, Corrosion Science, 68: 134-143.

Richtlinie, 1997. 97/23/EG des Europäischen Parlaments und des Rates. Angleichung der Rechtsvorschriften der Mitgliedstaaten über Druckgeräte. vom 29.Mai. 1997. S. 6-11,13-14, 20-30, 32-41. ABL. L 181 von 9.7.

Roeder, E., H.J.Bassler, M. Huber und J. Vollmar, 1992. Schwingungsrisskorrosionsverhalten des austenitischen Stahles X6CrNiMoTi 17 12 2 in 3\%iger $\mathrm{NaCl}$-Lösung unter Umlaufbiegebelastung, Werkstoffe und Korrosion, 43: 426-431.

Thomas, J.P.and R.P. Wei, 1992. Corrosion fatigue crack growth of steels in aqueous solutions I: Experimental results and modeling the effects of frequency and temperature, Material Science and Engineering, A159: 205-221.

Thorbjörnsson, I., 1995. Corrosion fatigue testing of eight different steels in an Icelandic geothermal environment, Materials and Design, 16(2): 97-102.

Unigovski, Ya.B., G. Lothongkum, E.M. Gutman, D. Alush, R. Cohen, 2009. Low-cycle fatigue behaviour of 316L-type stainless stell in chloride solutions, Corrosion Science, 51: 3014-3120.

Verband der Technischen Überwachungs-Vereine e. V. AD, 2000 Regelwerk. 1. Auflage. Berlin : Carl Heymaanns Verlag KG, 2004. ISBN: 3-452-25968-4. 
Citation: Anja Pfennig, 2018. In-situ experimental equipment to predict corrosion fatigue behavior of materials exposed to corrosive environment. Journal of Applied Sciences Research., 14(1): 25-31.

Wagner, 2007. Walter. Festigkeitsberechnung im Apparate- und Rohrleitungsbau. 7.Auflage. Würzburg : Vogel Fachbuch, 2007. 15(33): 178-181. ISBN-10: 3-8343-3075-2.

Wolf, M., 2013. Konstruktion eines Hochdrucksystems zur in-situ Untersuchung der SwRK metallischer Werkstoffe in korrosiven gasförmigen und flüssigen Medien bei hoer Temperatur, masterthesis, HTW-Berlin, 05/2013

Wolf, M., R. Afanasiev, T. Böllinghaus, A. Pfennig, 2016. Investigation of Corrosion Fatigue of Duplex Steel X2CrNiMoN22 53 Exposed to a Geothermal Environment under Different Electrochemical Conditions and Load Types, 13th International Conference on Greenhouse Gas Control Technologies, GHGT-13, 14-18 November 2016, Lausanne, Switzerland 